\title{
Income Distribution and Industrial Structure in China's Urban and Rural Areas
}

\author{
Guobin LIU*, Beibei SHI ${ }^{1}$ and Rong KANG \\ Northwest University, Xi'an, China; 2936612690@qq.com; pgyky412@163.com; kangrong@nwu.edu.cn \\ * Corresponding author: 2936612690@qq.com
}

\begin{abstract}
Since China's reform and opening up, China's economy has achieved a growth miracle. The people's income is constantly increasing, but according to World Bank statistics, Gini coefficient has exceeded the inequality warning line. The income distribution gap is getting bigger and bigger, which has become a serious problem China facing under the requirements of high-quality development. This article makes a brief theoretical analysis of the current situation of China's urban and rural income distribution and economic structure, and collected 31 provinces and cities, 9 consecutive years of panel data. The fixed effect model is used to empirically analyze the relationship between the urban and rural income distribution and industrial structure in various regions of China. The research results show that the upgrading of industrial structure has exacerbated the income distribution gap. Moreover, comparing the estimated parameters of the regression model between urban and rural areas, it is found that the impact of urban industrial structure upgrading on income disparity is more sensitive than that in rural areas.
\end{abstract}

Keywords: urban and rural; income distribution; industrial structure; Gini coefficient

JEL Classification: E64; L16; O18

\section{Introduction}

China's high-quality development goals in the report of the Fifth Plenary Session of the Nineteenth Central Committee paid special attention to the income distribution of residents. A key point in China's road to common prosperity is the rationality of income distribution. Normative analysis of economic issues often encounters the dilemma of fairness and efficiency. Income distribution is obviously related to the issue of equity. Excessive income distribution gaps will lead to social instability.

The process of China's industrialization continues to deepen, and the proportion of industrial added value in the industrial structure has gradually increased from the primary industry to the secondary and tertiary industries. With the continuous upgrading of the industrial structure, what is the income distribution situation in China?

The research perspectives on income distribution include: government transfer payments, human capital, tax regulation, production factor flow, industrial structure, etc. Among them, scholars who study tax regulation have found that China's tax system design is not very reasonable and needs to be improved. Income growth has an inverted U-shaped effect on income distribution. In particular, China's reform and opening up, rapid economic 
growth, and the mechanism of income distribution's influence on investment: income distribution pattern $\rightarrow$ income level $\rightarrow$ effective demand $\rightarrow$ capital accumulation and investment structure (Wang \& Cai, 2006). Conversely, the investment structure will also lead to the gap in income distribution. This article analyzes it as one of the reasons for the gap between urban and rural income distribution from the investment information channels in rural and urban areas. The flow of rural labor in China, on the one hand, increases the income of rural households, on the other hand, it has a positive effect on regulating income distribution and alleviating the gap between urban and rural areas (Li, 1999). The impact of industrial structure on income distribution, from the perspective of the different stages of China's economic development, with the 2008 financial crisis as the boundary, the previous advancement of the industrial structure will widen the income gap, and then there will be a trend of narrowing the income gap (Wu \& Liu, 2018).

This paper divides the structure of income distribution based on the above documents: income groups are divided into urban and rural areas, and income sources are divided into wages and investment income. Analyze the impact of the current industrial structure upgrade in China on the income distribution of residents in a deeper level, and establish analytical theories and classical mathematical model analysis to explain the expansion of the urban-rural income distribution gap. Corresponding suggestions are given to alleviate the impact of changes in the industrial structure on the income distribution of residents.

The following arrangement is as follows: the second part is the literature review, which sorts out the research on income distribution; the third part is the methodology, including theoretic mechanism, model establishment and data processing, establish benchmarks model based on hypotheses; the fourth part is the results, verify the proposed hypothesis; the fifth part is the discussion, robustness test of the regression results and empirical conclusions; the sixth part, Conclusions and recommendations, the process of upgrading China's industrial structure should weigh economic development and residents' income distribution, the distribution of industries between urban and rural areas should be rational, and investment information and channels should be smoother for urban and rural residents.

\section{Literature Review}

The impact on China's income distribution is mainly studied from the aspects of economic growth, fiscal revenue and expenditure, and education. The following documents are sorted out from these three aspects.

\section{Economic growth and income distribution:}

When the government follows the comparative advantage development strategy, income distribution will continue to decline in the process of economic development. When the government implements the strategy of prioritizing the development of heavy industry, economic development may stagnate, income distribution presents an inverted U-shaped characteristic of rising first and then falling, and steady-state income inequality is higher than the comparative advantage development strategy (Lin \& Chen, 2013). In the process of economic development of various countries in the world, the changing trend of labor share 
in the primary distribution shows a U-shaped law, and China is no exception (Li \& Liu, 2009). Financial repression has caused "unequal opportunities" in the financial market, and the wealth of the poor grows slowly, even falling into a poverty trap (Chen \& Lin, 2012). There is a co-integration relationship between China's economic growth and inequality in income distribution (Zhou, 2002). China's economic growth strategy and its impact on industrial structure will directly and indirectly affect income distribution through factor markets such as finance, products, and labor. In the pursuit of economic growth, we must avoid the poor from falling into a trap.

\section{Financial revenue and expenditure and income distribution:}

The income gap between urban and rural areas should be narrowed by increasing the proportion of labor remuneration in the primary distribution and reversing the urban bias of expenditures on science, education, culture, health, and welfare (Lei \& Cai, 2012). From the perspective of conducive to adjusting the distribution pattern of factor income, it is necessary for China to further adjust the current taxation policy and improve the taxation system (Guo $\& \mathrm{Lu}, 2011)$. Under China's current economic system and tax structure, the increase in the share of turnover taxes, income taxes, resource taxes, and property taxes will expand the gap in the distribution of market income between capital owners and labor owners. An increase in the share of behavioral taxes will narrow the income distribution gap between capital and labor (Li \& Geng, 2005). The problem of the overburden of farmers stems from China's urbanbiased national income distribution policy and the urban-rural dual tax system structure (Liu, 2001). Fiscal revenue and expenditure have substitution effect and income effect on income distribution. At present, China is undergoing a gradual tax system reform. It is necessary to rationally adjust the income of high-income groups and low-income groups and expand middle-income groups.

\section{Education and income distribution:}

The reduction of educational inequality in the long term has not improved income inequality, but income inequality in the current period, education inequality can be exacerbated (Yang \& Huang, 2008). There is an inverted U-shaped relationship between educational expansion and changes in income inequality. This inverted U-shaped change is the result of the expansion effect and the suppression effect of educational expansion (Lai, 1997). Education expansion may be more conducive to the income growth of the low-income population (Luo, 2007). Inequality in education will exacerbate income inequality (Bai, 2004). The investment in education mainly affects the investment in human capital. For the process of industrial upgrading in China, more and more high-quality talents are needed, so the income gap between education and residents may be reduced.

This article, based on the above literature, studies from the perspective of industrial structure, how China leads to the income distribution effect of urban and rural residents in the process of industrial structure? At the same time, the sensitivity of the income distribution gap between rural and urban residents to the upgrading of industrial structure is analyzed. 


\section{Methodology}

\subsection{Theoretic Mechanism}

The industrial structure is usually divided into three major industries, the primary industry, the secondary industry and the tertiary industry. The industrial structure upgrade we define here is that the total value added of the secondary and tertiary industries and the local GDP account for an increasing proportion.

The theoretical part of this article simply assumes that the products produced by the secondary and tertiary industries are capital-intensive. According to the current income situation in China, the investment structure is that people above middle income pay more attention to investment than people below middle income. As the process of industrialization continues to deepen and investment channels are becoming more diversified, the investment structure is becoming more obvious for people above and below middle income. China's industrial structure is upgraded. The income of people above the middle income is the return of capital plus wage income, while the income of people below the middle income plus a small amount of capital return (sometimes even without capital investment, there is no return of capital). Therefore, the industrialization upgrade will eventually lead to an increasing income gap. At the same time, considering that most industrialized enterprises gather in the suburbs of cities and towns and the service industry economy is more active in cities and towns. Rural investment channels and information are not as diverse and unobstructed as in urban areas, leading to certain resistance to the investment of middle-income and above people who are willing to invest in rural areas compared to middle-income people who are willing to invest in urban areas. Furthermore, in the process of upgrading China's industrial structure, the urban income gap is more sensitive to the upgrading of the industrial structure than the rural income gap. In other words, the sum of the added value of the secondary and tertiary industries accounts for a percentage of the local area's GDP. The ratio changes by $1 \%$, and the effect of expanding the urban income gap in this region is stronger than the effect of expanding the rural income gap in this region.

In order to understand the above theories more deeply, a simple mathematical economic model analysis is established:

Assume that the production function of the firm is the C-D production function, with two elements input, labor L, wages w; capital K, interest rates r. Residents provide labor and invest in enterprises. In a perfectly competitive market, corporate profits are zero. The output value of the product is all transformed into the return of the input elements.

$$
F(K, L)=A K^{\alpha} L^{\beta} \quad \alpha+\beta=1
$$

The conditions that the enterprise pursues the principle of theoretical maximization: $M P K=r, M P L=w$

According to Euler's theorem (product is exhausted): $\frac{\partial F}{\partial K} \cdot K+\frac{\partial F}{\partial L} \cdot L=F$ which is, $r \cdot K+w \cdot L=F$ 
The products produced by the secondary and tertiary industries are capital-intensive. The more capital invested by the middle-income, the larger the product distribution. The income distribution gap will widen.

Based on theoretical analysis, the following hypotheses are proposed:

1. The income gap between residents will continue to widen as the industrial structure upgrades

2. With the continuous upgrading of industrial structure, the effect of expanding urban income gap is stronger than the effect of expanding rural income gap in the region

\subsection{Model Establishment}

This paper refers to the literature (Liu \& Liu, 2019) and selects the control variables, thus establishing the following benchmark model:

$$
g n i_{i t}=\beta_{0}+\beta_{1} \times \text { instru }_{\text {it }}+\beta_{3} \times \text { instru }_{\text {it }} *_{\text {inrate }}+\beta_{4} \times X_{i t}+\theta_{i}+\gamma_{t}+u_{i t}
$$

Among them, the explained variable is gni, and the Gini coefficient of the region is the urban (ugni) and rural Gini coefficient (cgni). The core explanatory variables are: instru, an indicator of industrial structure, used to describe the upgrading of industrial structure, using the sum of the added value of the secondary industry and the tertiary industry divided by the regional gross product. The interaction term instru*inrate, where inrate is the industrialization rate, is obtained by dividing the secondary industry by the region's GDP. The introduction of interaction terms is to verify whether China's industrialization rate continues to advance, whether it will play a role in the impact of industrial structure on income distribution. $X$ represents a series of control variables. The control variables sought in this article are: proxy variables of economic development level, GDP per capita: lngdppc and the square term lngdppcsq; the introduction of the square term is due to Kuznets's inverted $U$ theory; the capital formation rate (invest), which uses the total fixed capital formation divided by the regional GDP; the degree of trade openness (lntrade), is the region's imports divided by the regional GDP; foreign countries direct investment (fdi), expressed as the ratio of the total foreign direct investment to the regional GDP; urbanization rate (urb), the ratio of the urban population to the area's permanent population; education level (edu), the ratio of the number of people receiving high school and above to the total number of people in the sample.

\subsection{Data Processing}

The data source of this article: collect the original data of the China Statistical Yearbook, and use the calculation method of the Gini coefficient in Tian Weimin's article "Calculation of China's Gini Coefficient and Analysis of Its Change Trend" to obtain the Gini coefficient of cities and rural areas in various regions. All other raw data comes from the National Bureau of Statistics.

Explanation for the treatment of variable observations: Foreign direct investment (fdi) uses the total amount of foreign direct investment to compare the gross product of the region, and directly uses the original value to calculate the ratio, and there is no unified unit. The reason for this is that the unified unit method is to multiply by the average exchange rate and 
the magnitude multiplier. The total conversion effect is a specific multiple value. In the measurement regression, only the coefficient multiple changes. It will not affect the positive or negative of the regression coefficient and significance. Similarly, there is no unified unit for the degree of trade openness (Intrade), and considering that the value of the direct ratio is still relatively large, the logarithm is taken on the basis of the ratio to obtain the variable observation value in the econometric regression.

\section{Results}

\subsection{Unit Root Test}

First of all, because it is panel data. Each sequence of variables to be regressed is tested for stationarity. It is found that except for the urbanization rate (urb) and education level (edu) which are series with a time trend, the other variable series are all stationary series.

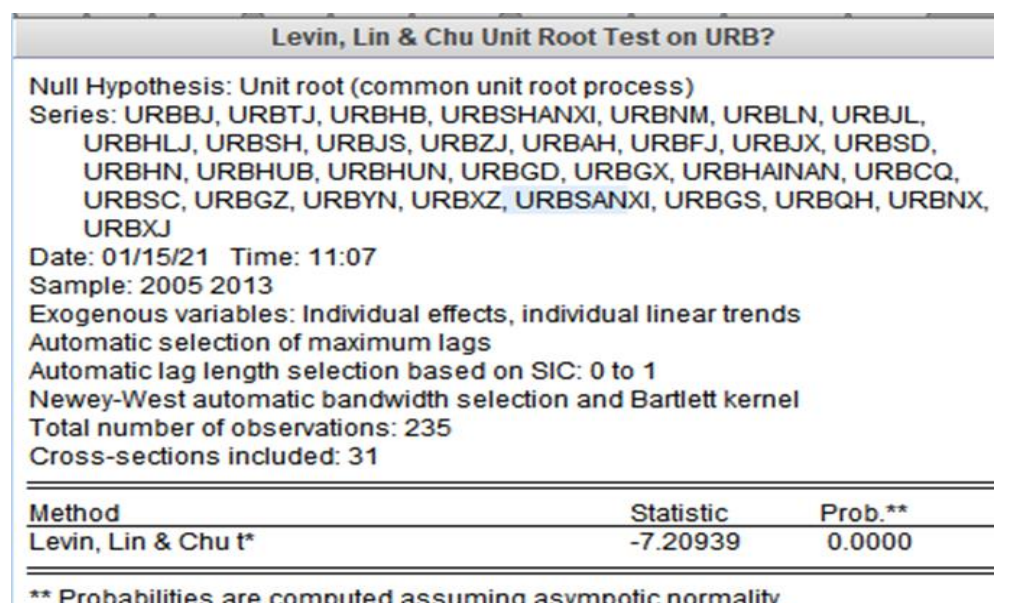

Figure 1. Unit root test.

The above figure is an LLC unit root test with a time trend item on the urbanization rate (urb) sequence. The test result is that there is no unit root. Therefore, the urbanization rate (urb) sequence is a sequence with a time trend.

In the same way, found that edu is also a series with time trend. Therefore, urb and edu, two explanatory variables cannot be directly added to the model regression.

\subsection{Choose the Most Reasonable Model}

In addition to urb and edu, all other variables are added for step regressions. In this paper, two sets of regressions are performed, and the explained variables are: urban Gini coefficient (ugni) and rural Gini coefficient (cgni).

\section{- The explained variable is ugni:}

First do a simple cross-sectional regression of stacked data, without selecting crosssection and time effects, use the EGLS method to perform regression estimation. 


\begin{tabular}{|c|c|c|c|c|}
\hline \multicolumn{5}{|c|}{$\begin{array}{l}\text { Dependent Variable: UGNI? } \\
\text { Method: Pooled EGLS (Cross-section weights) } \\
\text { Date: } 02 / 23 / 21 \text { Time: } 11: 43 \\
\text { Sample: } 20052013 \\
\text { Included observations: } 9 \\
\text { Cross-sections included: } 31 \\
\text { Total pool (balanced) observations: } 279 \\
\text { Linear estimation after one-step weighting matrix }\end{array}$} \\
\hline Variable & Coefficient & Std. Error & $\mathrm{t}$-Statistic & Prob. \\
\hline INSTRU? & 0.405126 & 0.036149 & 11.20704 & 0.0000 \\
\hline LNGDPPC? & 0.014206 & 0.004828 & 2.942628 & 0.0035 \\
\hline LNGDPPCSQ? & -0.000386 & 0.000240 & -1.610093 & 0.1085 \\
\hline INVEST? & 0.004682 & 0.012051 & 0.388503 & 0.6979 \\
\hline FDI? & -0.001153 & 0.000278 & -4.149641 & 0.0000 \\
\hline LNTRADE? & -0.002774 & 0.002265 & -1.224503 & 0.2218 \\
\hline \multicolumn{5}{|c|}{ Weighted Statistics } \\
\hline R-squared & 0.553505 & \multirow{4}{*}{\multicolumn{2}{|c|}{$\begin{array}{l}\text { Mean dependent var } \\
\text { S.D. dependent var } \\
\text { Sum squared resid }\end{array}$}} & 0.595046 \\
\hline Adjusted R-squared & 0.545328 & & & 0.299343 \\
\hline S.E. of regression & 0.031761 & & & 0.275394 \\
\hline Durbin-Watson stat & 0.438655 & & & \\
\hline \multicolumn{5}{|c|}{ Unweighted Statistics } \\
\hline R-squared & 0.358963 & \multirow{2}{*}{\multicolumn{2}{|c|}{$\begin{array}{l}\text { Mean dependent var } \\
\text { Durbin-Watson stat }\end{array}$}} & 0.440957 \\
\hline Sum squared resid & 0.296668 & & & 0.247106 \\
\hline
\end{tabular}

Figure 2. Invariant coefficient model regression.

It is found that the residual sum of squares of the statistical model estimated after weighting is 0.2754 , which is smaller than the estimated value of 0.2967 for the model without weighted estimation. At the same time, the estimated model fits better after weighting. Looking at the DW statistical value of the weighted model test is only 0.4387 , indicating that there is a correlation between the residual series.

Therefore, it is unreasonable to directly use a simple regression model. Let's check whether the panel data regression should use a fixed effects model or a random effects model? The Hausmann random effects test was performed on the model.

Correlated Random Effects - Hausman Test
Pool: GNI
Test cross-section random effects
\begin{tabular}{lrrr}
\hline Test Summary & Chi-Sq. Statistic & Chi-Sq. d.f. & Prob. \\
\hline \hline Cross-section random & 26.536443 & 7 & 0.0004 \\
\hline \hline
\end{tabular}

Figure 3. Hausman random effects test.

The test result is that random effects are rejected. Therefore, it is suitable to use a fixed effects model for regression estimation.

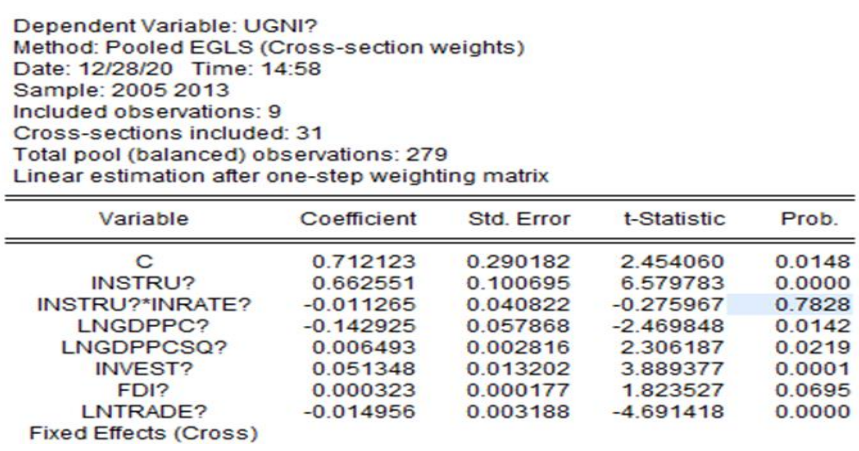

Figure 4. Fixed effects model regression (weighted). 
Although the model fit is good, the coefficients of some variables (interaction term: instrument*inrate) failed the $t$ test. Thus, the model needs to continue to be revised.

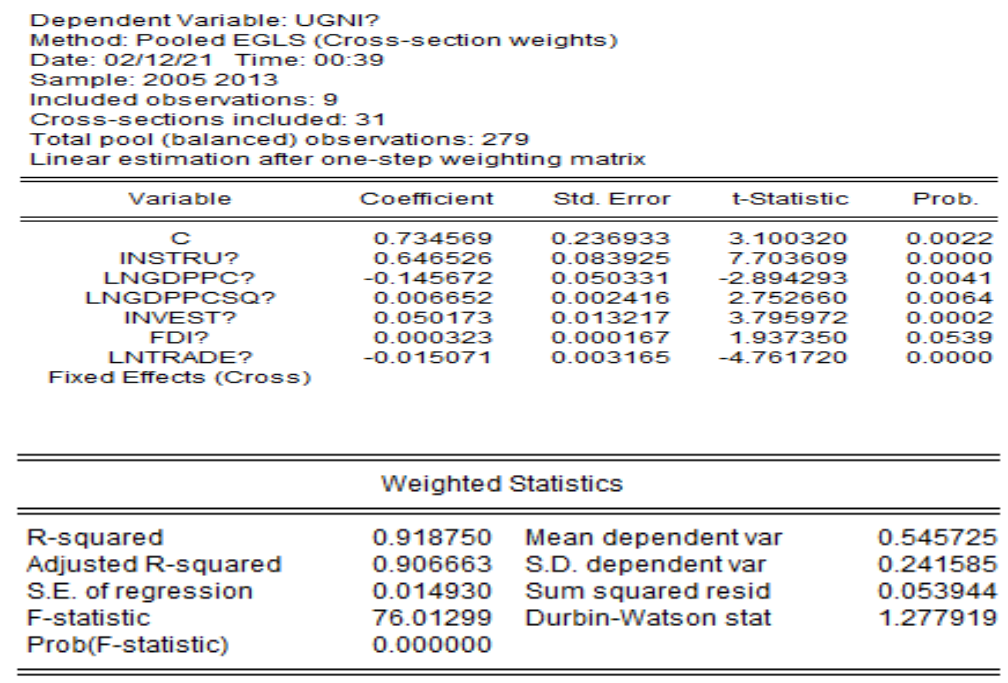

Figure 5. Final model regression determined after screening variables.

Screening variables and using the fixed effects model, using the EGLS estimation method, found that the adjusted coefficient of determination was 0.9. The DW statistic is 1.28, which is relatively close to 2 . It can be considered that the correlation of the residual sequence is weak. The resulting estimation results are credible. Based on the results of the above figure, we analyze the impact of the selected variables on the urban income gap:

The greater the proportion of the combined secondary and tertiary industries in the local area's GDP, the larger the urban income gap in the region. Economic growth will reduce the income gap. At the same time, it is verified that the relationship between economic growth and income gap is not Kuznets inverted U-shaped, but U-shaped. At the same time, combining the two proxy variables of economic growth, my country's economic growth It is still on the left side of the $U$ shape, so economic growth will reduce the income gap. An increase in the investment formation rate will widen the income gap between urban residents. The possible reason is that high-income earners will invest more, which will result in more capital income than low-income earners and widen the income gap. The greater the amount of foreign direct investment, the greater the income gap between urban residents, but the significance is not very large, only a significant level of $10 \%$. The greater the degree of opening to the outside, the smaller the income gap among urban residents.

\section{- The explained variable is cgni:}

Similar to the above process, here is just to show the most reasonable regression results for analysis. 


\begin{tabular}{|c|c|c|c|c|}
\hline \multicolumn{5}{|c|}{$\begin{array}{l}\text { Dependent Variable: CGNI? } \\
\text { Method: Pooled EGLS (Cross-section weights) } \\
\text { Date: } 02 / 23 / 21 \text { Time: } 07: 48 \\
\text { Sample: } 20052013 \\
\text { Included observations: } 9 \\
\text { Cross-sections included: } 31 \\
\text { Total pool (balanced) observations: } 279 \\
\text { Linear estimation after one-step weighting matrix }\end{array}$} \\
\hline Variable & Coefficient & Std. Error & t-Statistic & Prob. \\
\hline $\begin{array}{l}\text { C } \\
\text { INSTRU? } \\
\text { LNGDPPC? } \\
\text { LNGDPPCSQ? } \\
\text { INVEST? } \\
\text { FDI? } \\
\text { LNTRADE? } \\
\text { Fixed Effects (Cross) }\end{array}$ & $\begin{array}{r}0.860908 \\
0.556826 \\
-0.182509 \\
0.009851 \\
0.091100 \\
0.000476 \\
-0.020422\end{array}$ & $\begin{array}{l}0.356056 \\
0.123118 \\
0.075978 \\
0.003677 \\
0.019920 \\
0.000251 \\
0.004037\end{array}$ & $\begin{array}{r}2.417899 \\
4.522687 \\
-2.402143 \\
2.678932 \\
4.573301 \\
1.895586 \\
-5.058840\end{array}$ & $\begin{array}{l}0.0164 \\
0.0000 \\
0.0171 \\
0.0079 \\
0.0000 \\
0.0592 \\
0.0000\end{array}$ \\
\hline \multicolumn{5}{|c|}{ Weighted Statistics } \\
\hline $\begin{array}{l}\text { R-squared } \\
\text { Adjusted R-squared } \\
\text { S.E. of regression } \\
\text { F-statistic } \\
\text { Prob(F-statistic) }\end{array}$ & $\begin{array}{l}0.838701 \\
0.814706 \\
0.020984 \\
34.95327 \\
0.000000\end{array}$ & \multicolumn{2}{|c|}{$\begin{array}{l}\text { Mean dependent var } \\
\text { S.D. dependent var } \\
\text { Sum squared resid } \\
\text { Durbin-Watson stat }\end{array}$} & $\begin{array}{l}0.491003 \\
0.152065 \\
0.106557 \\
1.773816\end{array}$ \\
\hline
\end{tabular}

Figure 6. Regression results of the final selected model for rural areas.

Analysis of the impact of each selected variable on the rural income gap: because the regression results are consistent with the urban regression results. The conclusion drawn here is consistent with that of the town.

Let's analyze the difference between urban and rural areas (Table 1):

Table 1. Comparison of estimated coefficients between urban and rural areas (fixed effect model).

\begin{tabular}{|c|c|c|}
\hline Variables & $\begin{array}{c}\text { Coefficient for } \\
\text { citys and towns }\end{array}$ & $\begin{array}{c}\text { Coefficient for } \\
\text { rural areas }\end{array}$ \\
\hline instru & 0.646525872 & 0.556825659 \\
\hline lngdppc & -0.14567215 & -0.18250945 \\
\hline lngdppcsq & 0.006651755 & 0.009850525 \\
\hline invest & 0.050173008 & 0.091100037 \\
\hline fdi & 0.000323145 & 0.000476049 \\
\hline Intrade & -0.0150705 & -0.02042154 \\
\hline
\end{tabular}

Comparing the estimated coefficients of the explanatory variables between urban and rural areas, it can be found that the impact of industrial structure upgrading on the expansion of urban income gap is greater than that in rural areas. The effects of other explanatory variables are stronger than those in urban areas.

\section{Discussion}

Switch to stata software to perform regression on the explained variables as ugni and cgni respectively, estimate the regression coefficients, and use different estimation methods to compare and analyze the robustness of the regression results. The results are analyzed as follows: 
Table 2. The explained variable is the urban Gini coefficient, and the robustness test.

\begin{tabular}{|c|c|c|c|c|c|c|}
\hline & (1) & (2) & (3) & (4) & (5) & (6) \\
\hline & OLS & BE & FE & FE_robust & RE_fgls & RE_mle \\
\hline \multirow[t]{2}{*}{ instru } & $0.346^{* * *}$ & 0.0861 & $0.575^{* * *}$ & $0.575^{* * *}$ & $0.536^{* * *}$ & $0.553^{* * *}$ \\
\hline & $(0.0850)$ & $(0.177)$ & $(0.104)$ & $(0.150)$ & $(0.0803)$ & $(0.0802)$ \\
\hline \multirow[t]{2}{*}{$\operatorname{lngdppc}$} & 0.203 & 0.578 & -0.0991 & -0.0991 & -0.0804 & -0.0894 \\
\hline & $(0.141)$ & $(0.468)$ & $(0.0606)$ & $(0.0974)$ & $(0.0949)$ & $(0.0566)$ \\
\hline \multirow[t]{2}{*}{ lngdppcsq } & -0.00931 & -0.0255 & 0.00450 & 0.00450 & 0.00374 & 0.00413 \\
\hline & $(0.00681)$ & $(0.0236)$ & $(0.00294)$ & $(0.00477)$ & $(0.00464)$ & $(0.00276)$ \\
\hline \multirow[t]{2}{*}{ invest } & -0.0142 & 0.00553 & $0.0533^{* * *}$ & $0.0533^{*}$ & 0.0376 & $0.0423^{* * *}$ \\
\hline & $(0.0436)$ & $(0.0553)$ & $(0.0155)$ & $(0.0282)$ & $(0.0244)$ & $(0.0150)$ \\
\hline \multirow[t]{2}{*}{ fdi } & -0.000911 & $-0.00361^{* *}$ & 0.000307 & $0.000307^{* * *}$ & $0.000296^{* * *}$ & $0.000310^{*}$ \\
\hline & $(0.000779)$ & $(0.00131)$ & (0.000193) & (0.0000708) & $(0.0000786)$ & (0.000187) \\
\hline \multirow[t]{2}{*}{ lntrade } & -0.00294 & 0.00214 & $-0.0156^{* * *}$ & $-0.0156^{* * *}$ & $-0.0105^{* * *}$ & $-0.0117^{* * *}$ \\
\hline & $(0.00689)$ & $(0.0118)$ & $(0.00388)$ & $(0.00484)$ & $(0.00336)$ & $(0.00327)$ \\
\hline \multirow[t]{2}{*}{ _cons } & -0.927 & -2.866 & $0.550^{* *}$ & 0.550 & 0.447 & $0.488^{*}$ \\
\hline & $(0.708)$ & $(2.418)$ & $(0.279)$ & $(0.485)$ & $(0.479)$ & $(0.272)$ \\
\hline \multirow[t]{2}{*}{ _cons(sigma_u) } & & & & & & $0.0327^{* * *}$ \\
\hline & & & & & & $(0.00444)$ \\
\hline \multirow[t]{2}{*}{ _cons(sigma_e) } & & & & & & $0.0149^{* * *}$ \\
\hline & & & & & & $(0.000671)$ \\
\hline $\mathrm{N}$ & 279 & 279 & 279 & 279 & 279 & 279 \\
\hline $\mathrm{R} 2$ & 0.383 & 0.610 & 0.283 & 0.283 & & \\
\hline
\end{tabular}

The regression results in Table 2 and Table 3: The column (1) is the robust ordinary least squares estimation; the column (2) is the regression estimation between groups; the columns (3) and (4) are the fixed effects regression, among which Column (4) is the result of robust fixed-effects regression; column (5) and (6) are random-effects regression and are the results of feasible generalized least squares and maximum likelihood estimation respectively.

It can be found that the coefficients of the core explanatory variables of the industrial structure are only insignificant in the between groups regression result, and the others are all significantly positive, and the result is robust.

We also introduce the educational indicators (edu) and urbanization rate (urb) with a time trend to conduct regression robustness tests and finds that the core explanatory variable of industrial structure is still robust. By changing the year and selecting other years for estimation, the results are robust.

At the same time, comparing the regression coefficients of each column in urban (Table 2) and rural (Table 3), it is found that the conclusion of sensitivity is still consistent with the conclusion of the previous analysis. 
Table 3. The explained variable is the rural Gini coefficient, and the robustness test.

\begin{tabular}{|c|c|c|c|c|c|c|}
\hline & (1) & (2) & (3) & (4) & (5) & (6) \\
\hline & OLS & BE & FE & FE_robust & RE_fgls & RE_mle \\
\hline \multirow[t]{2}{*}{ instru } & $0.216^{* *}$ & 0.0935 & $0.542^{* * *}$ & $0.542^{* *}$ & $0.357^{* * *}$ & $0.388^{* * *}$ \\
\hline & $(0.0873)$ & $(0.162)$ & $(0.146)$ & $(0.198)$ & $(0.0708)$ & $(0.0932)$ \\
\hline \multirow[t]{2}{*}{$\operatorname{lngdppc}$} & 0.223 & 0.669 & $-0.156^{*}$ & -0.156 & -0.0626 & -0.0852 \\
\hline & $(0.144)$ & $(0.427)$ & $(0.0850)$ & $(0.105)$ & $(0.106)$ & $(0.0778)$ \\
\hline \multirow[t]{2}{*}{$\operatorname{lngdppcsq}$} & -0.00914 & -0.0304 & $0.00863^{* *}$ & 0.00863 & 0.00445 & 0.00549 \\
\hline & $(0.00694)$ & $(0.0215)$ & $(0.00412)$ & $(0.00512)$ & $(0.00513)$ & $(0.00381)$ \\
\hline \multirow[t]{2}{*}{ invest } & -0.00534 & 0.00702 & $0.0822^{* * *}$ & $0.0822^{* *}$ & $0.0510^{* *}$ & $0.0586^{* * *}$ \\
\hline & $(0.0395)$ & $(0.0505)$ & $(0.0218)$ & $(0.0307)$ & $(0.0259)$ & $(0.0204)$ \\
\hline \multirow[t]{2}{*}{ fdi } & -0.000944 & $-0.00311^{* *}$ & $0.000471^{*}$ & $0.000471^{* * *}$ & $0.000290^{*}$ & 0.000353 \\
\hline & $(0.000840)$ & $(0.00119)$ & $(0.000271)$ & $(0.0000764)$ & $(0.000159)$ & $(0.000259)$ \\
\hline \multirow[t]{2}{*}{ lntrade } & -0.00821 & 0.00213 & $-0.0179^{* * *}$ & $-0.0179^{* *}$ & $-0.0136^{* * *}$ & $-0.0144^{* * *}$ \\
\hline & $(0.00617)$ & $(0.0108)$ & $(0.00544)$ & $(0.00671)$ & $(0.00397)$ & $(0.00394)$ \\
\hline \multirow[t]{2}{*}{ _cons } & -1.006 & -3.296 & $0.714^{*}$ & 0.714 & 0.355 & 0.451 \\
\hline & $(0.726)$ & (2.206) & $(0.391)$ & $(0.522)$ & $(0.527)$ & $(0.380)$ \\
\hline \multirow[t]{2}{*}{ _cons(sigma_u) } & & & & & & $0.0283^{* * *}$ \\
\hline & & & & & & $(0.00409)$ \\
\hline \multirow[t]{2}{*}{ _cons(sigma_e) } & & & & & & $0.0209^{* * *}$ \\
\hline & & & & & & $(0.000947)$ \\
\hline $\mathrm{N}$ & 279 & 279 & 279 & 279 & 279 & 279 \\
\hline $\mathrm{R} 2$ & 0.430 & 0.594 & 0.461 & 0.461 & & \\
\hline
\end{tabular}

Standard errors in parentheses

${ }^{*} \mathrm{p}<0.1,{ }^{* *} \mathrm{p}<0.05,{ }^{* * *} \mathrm{p}<0.01$

The regression results in Table 2 and Table 3: The column (1) is the robust ordinary least squares estimation; the column (2) is the regression estimation between groups; the columns (3) and (4) are the fixed effects regression, among which Column (4) is the result of robust fixed-effects regression; column (5) and (6) are random-effects regression and are the results of feasible generalized least squares and maximum likelihood estimation respectively.

It can be found that the coefficients of the core explanatory variables of the industrial structure are only insignificant in the between groups regression result, and the others are all significantly positive, and the result is robust.

We also introduce the educational indicators (edu) and urbanization rate (urb) with a time trend to conduct regression robustness tests and finds that the core explanatory variable of industrial structure is still robust. By changing the year and selecting other years for estimation, the results are robust.

At the same time, comparing the regression coefficients of each column in urban (Table 2) and rural (Table 3), it is found that the conclusion of sensitivity is still consistent with the conclusion of the previous analysis. 


\section{Conclusions and Recommendations}

This paper finds that with the continuous upgrading of China's industrial structure, the income gap between rural and urban residents is widening. At the same time, comparing the income gap between urban and rural residents, it is found that the income distribution effect between rural and urban is basically similar. The only difference is that the Gini coefficient fluctuates relatively more in rural areas over time. Empirical analysis of the effect of expanding the income gap between urban residents is greater and more sensitive than the effect of expanding the income gap in rural areas.

Economic growth will reduce the income gap, and at the same time verify that the relationship between economic growth and income gap is not Kuznets inverted U-shaped, but U-shaped, and my country's economic growth is still on the left side of the U-shaped. Therefore, economic growth will reduce the income gap. An increase in the investment formation rate will widen the income gap between urban residents. The possible reason is that high-income earners will invest more, which will result in more capital income than lowincome earners and widen the income gap. The greater the amount of foreign direct investment, the greater the income gap between urban residents, but the significance is not very large, only a significant level of $10 \%$. The greater the degree of opening to the outside, the smaller the income gap among urban residents.

In the process of upgrading the industrial structure, we must weigh the relationship between economic growth and residents' income distribution. Reasonable income distribution of residents is conducive to social harmony and stability, and will further improve the quality of industrial structure upgrading.

The geographic distribution of China's industries needs to be improved. It is necessary to make the investment information and channels between urban and rural areas more convenient and transparent, which will be more conducive to the capital flow of the rural and urban populations above the average level, and the population below the average level can also be transparent. Increase the amount of investment in diversified channels to increase capital income to help adjust the previously monotonous income structure, and also make income sources more diverse and stable.

Actively promote the opening up of regions and smooth the flow of products and factors of production between regions. This is more conducive to the rational allocation of resources, and people's income distribution is more diversified.

Acknowledgments: This research was funded by Shanxi Provincial Department of Education 2020 General Special Scientific Research Project (No. 20JK0367), China-Central Eastern European Countries Higher Joint Education Project (No. 202028) Shanxi Provincial Social Scientific Circles 2020 Major Theoretical and Practical Research Project(No. 2020Z287), Shanxi Financial Assets 2021 Major Research Project (No. 20JZ-41).

\section{References}

Bai X. (2004). Education and Income Inequality: An Empirical Study in China. Management World, 06, 53-58. https://doi.org/10.19744/j.cnki.11-1235/f.2004.06.006

Chen, B., \& Lin, Y. (2012). Financial Repression, Industrial Structure and Income Distribution. World Economy, 35(1), 3-23. http://www.cnki.com.cn/Article/CJFDTotal-SJJJ201201004.htm 
Guo, Q., \& Lu, B. (2011). On the influence of taxation on the distribution of essential income. Economic Research, 46(6), 16-30. http://www.cnki.com.cn/Article/CJFDTotal-JJYJ201106003.htm

Lai, D. (1997). Educational Expansion and Income Inequality. Economic Research, 10, 46-53. http://www.cnki.com.cn/Article/CJFDTotal-JJYJ710.006.htm

Lei, G., \& Cai, X. (2012). Primary distribution distortion, fiscal expenditure city bias and urban-rural income gap: Empirical evidence from China's provincial panel data. Quantitative Economics and Technical Economic Research, 29(3), 76-89. https://doi.org/10.13653/j.cnki.jqte.2012.03.011

Lin, Y., \& Chen, B. (2013). Development strategy - industrial structure and income distribution. Economics (Quarterly), 12(4), 1109-1140. https://doi.org/10.13821/j.cnki.ceq.2013.04.016

Li, D., Liu, L., \& Wang, H. (2009). U-shaped law of labor share evolution in GDP. Economic Research, 44(1), 70-82. http://www.cnki.com.cn/Article/CJFDTotal-SHEK200904011.htm

Li, S., \& Geng, Y. (2005). China's tax structure, economic growth and income distribution. Economic Research, 05, 118-126. http://www.cnki.com.cn/Article/CJFDTOTAL-JJYJ200505011.htm

Liu, S. (2001). Unifying the urban and rural tax system and adjusting the distribution policy: a new theory of reducing the burden on farmers. Economic Research, 02, 43-49+60. http://www.cnki.com.cn/Article/CJFDTotal-JJYJ200102005.htm

Luo, C. (2007). The rate of return to education for urban residents and its distribution characteristics. Economic Research, 06, 119-130. http://www.cnki.com.cn/Article/CJFDTotal-JJYJ200706010.htm

$\mathrm{Wu}, \mathrm{W} ., \mathrm{Liu}, \mathrm{Y} .$, \& Xu, L. (2018). Industrial structure change and income inequality: micro-evidence from China. Management World, 34(2), 22-33. https://doi.org/10.19744/j.cnki.11-1235/f.2018.02.003

Yang, J., Huang, X., \& Li, X. (2008). Educational Inequality and Income Distribution Gap: An Empirical Analysis of China. Management World, 01, 38-47+187. https://doi.org/10.19744/j.cnki.11-1235/f.2008.01.006

Zhou, W. (2002). Empirical analysis of the relationship between income distribution and economic growth of Chinese urban residents. Economic Science, 01, 40-47. https://doi.org/10.19523/j.jjkx.2002.01.005

Zou, W., \& Zhang, F. (2006). Income differences and human capital accumulation in rural areas. Chinese Social Sciences, 02, 67-79+206. http://www.cnki.com.cn/Article/CJFDTOTAL-ZSHK200602006.htm 